\title{
Impression Management Versus Intrapsychic Explanations in Social Psychology: A Useful Dichotomy?
}

\author{
Philip E. Tetlock and A. S. R. Manstead \\ University of California, Berkeley
}

\begin{abstract}
Impression management refers to the behavioral strategies that people use to create desired social images or identities. This article focuses on the current status of impression management explanations in social psychology. We argue that the common practice of referring to impression management theory is misleading. Many potential theories of impression management exist, each based on distinct assumptions. We also review the methodological strategies that investigators have used to distinguish between impression management and intrapsychic explanations for a variety of research findings. Although empirical confrontations between impression management and intrapsychic explanations have stimulated innovative research, there are serious limits on the discriminability of the two classes of explanation. The dichotomy between impression management and intrapsychic processes is arbitrary. We conclude by discussing possible conceptual frameworks for integrating the psychological processes described by both impression management and intrapsychic explanations.
\end{abstract}

Social-psychological theorists have long emphasized the fundamental importance of impression management in interpersonal behavior (e.g., Cooley, 1902; James, 1890; Mead, 1934). What people say and do frequently represent attempts to create desired impressions on others. Many contemporary writers have reaffirmed and built on this key notion (Jones \& Pittman, 1982; Schlenker, 1980; Snyder, 1979; Tedeschi, 1981).

Impression management explanations for behavior have, however, only recently become influential in experimental social psychology. During the 1960s and 1970s, experimental social psychologists revealed a marked preference for intrapsychic explanations that focused on the cognitive or motivational processes of the individual, without reference to

This article was written while the second author was on leave at the University of California, Berkeley. The assistance of a Fullbright travel grant is gratefully acknowledged.

We appreciate the constructive comments of David Buss, Anthony Greenwald, Robent Hogan, Harry Reis, Gün Semin, James Tedeschi, and an anonymous reviewer on an earlier version of this article.

Requests for reprints should be sent to either Philip E. Tetlock, Department of Psychology, University of California, Berkeley, California 94720 , or to A. S. R. Manstead, Department of Psychology, University of Manchester, Manchester, M13 9PL, England. social context (e.g., attribution theories, cognitive consistency theories, equity theory). Advocates of the impression management perspective have now begun to challenge this long-standing dominance of intrapsychic theories. They have proposed impression management interpretations for an enormous range of experimental findings, including attitude moderation in the forced compliance paradigm (Schlenker, 1982; Tedeschi \& Rosenfeld, 1981), attitude polarization in groups (Jellison \& Arkin, 1977), responses to threats to behavioral freedom (Baer, Hinkle, Smith, \& Fenton, 1980), defensive and counterdefensive explanations for task performance (Tetlock, 1981; Weary \& Arkin, 1981), equity and equality rules in reward allocation decisions (Reis, 1981), determinants of helping behavior (Baumeister, 1982) and aggression (Felson, 1981), anticipatory attitude change (Cialdini, Petty \& Cacioppo, 1981), classical and operant conditioning of attitudes (Page, 1981), deindividuation (Lindskold \& Propst, 1981), and conformity (Baumeister, 1982).

Our primary goal in this article is to place impression management explanations in a broad theoretical context. The article is divided into three sections. In the opening section, we propose that the common practice of referring to impression management theory is misleading. There are numerous possible 
theories of impression management, each based on distinct assumptions. Researchers have, moreover, only begun to explore the conceptual subtleties and complexities of the impression management position: Many more theories can be expected to emerge. In the second section, we explore recent attempts to distinguish impression management explanations of experimental findings from intrapsychic explanations such as cognitive dissonance, reactance, equity, and ego-defensive theories. We examine the methodological strategies investigators have used to differentiate the two competing classes of explanation and conclude that no strategy has yieldedor is likely to yield-decisive evidence. In the final section, we propose that the dichotomy between impression management and intrapsychic explanations is arbitrary. The two classes of explanation are fuzzy sets (Mervis \& Rosch, 1981) that blur into each other. The search for crucial experiments should be abandoned in favor of the more modest, but realistic, goal of describing the types of private and public identities that constrain and guide our social behavior.

\section{Current State of the Impression} Management Research Program

Lakatos's (1970) concept of research program offers a useful framework for organizing existing work on impression management. Lakatos argued that the appropriate unit for describing scientific progress is not the isolated hypothesis or even theory, but the research program. Research programs can extend over decades and inspire an enormous amount of theoretical and empirical work. Underlying all of the diverse activity inspired by a research program is, however, a hard core of basic, unmodifiable assumptions about the subject matter. This hard core gives coherence, impetus, and direction to the research program. The primary objective of the scientific community is to develop and test theories compatible with the hard core.

\section{Immaturity of the Impression Management Research Program}

Current work on impression management represents an early stage in the development of a research program. The hard core of the incipient program is a particular view of human nature: People are highly sensitive to the social significance of their conduct and are motivated to create desired identities in interpersonal encounters. These hard core assumptions provide the starting point for theory and research on impression management. Investigators should proceed as if the hard core were true. Their task is to articulate and refine the hard core, not to challenge it. Even within this constraint, however, there remains much room for disagreement. Heated (within-research-program) debates may emerge over such questions as: What types of impressions do people seek to create on others? What is the, motivational basis for impression management? Whom do people seek to impress? What behavioral tactics do people use to achieve desired identities? What is the relative importance of personality and situational variables as determinants of identity goals and tactics? How competent or effective are people as impression managers? Is impression management necessarily duplicitous or do people sometimes truly believe in the identities they claim?

The immaturity of the research program is reflected in the absence of widely shared answers to these questions within the scientific community. One can accept the hard core of the program but take a variety of positions on specific issues concerning the nature of impression management. Little consensus exists on the form that a comprehensive theory of impression management should take. Consider, for instance, the range of answers researchers can give to basic questions on the meaning of impression management.

What types of impressions do people seek to create on others? It is tempting to posit simply that people seek "socially desirable" identities-to portray themselves as possessing culturally valued traits or characteristics (e.g., likable, intelligent). Without question, people often seek culturally valued identities. Important qualifications, however, need to be attached to such an assertion. For one thing, what counts as a desirable identity varies sharply from one cultural-historical setting to another (Schlenker, 1980). Second, even restricting discussion to one social system at a given time, people do not always claim socially desirable identities. On occasion, they 
try to intimidate rivals or opponents by emphasizing their own toughness, bad temper, and even irrationality. On other occasions, they emphasize their weakness and dependency in order to secure the protection of powerful others (cf. Jones \& Pittman, 1982).

What motives underlie impression management? The above discussion reveals little limit to the range of identities people try to claim in interpersonal relationships. This wide variety of identity objectives reflects the wide variety of needs that theorists have proposed to motivate impression management. One basic distinction is between defensive and assertive impression management (Arkin, 1981; Schlenker, 1980, 1982; Tedeschi \& Norman, in press). Defensive impression management is designed to protect an individual's established social image; it is triggered by negative affective states (e.g., embarrassment, shame) activated by perceived threats to one's social image. Assertive impression management is designed to improve an individual's social image; it is triggered by selfenhancing motives activated by perceived opportunities for creating favorable impressions on others. Another basic distinction is in the explanations that theorists offer for why people are motivated to protect or improve their social identities. The most influential hypothesis has been that people seek approval and respect, and avoid disapproval and disrespect, as ends in themselves (cf. Hogan, 1982; Linton, 1945). Other motives have, however, been proposed, including public validation for one's self-concept (Baumeister, 1982; Sullivan, 1953; Swann \& Read, 1981), bargaining power in interpersonal relationships (Jones \& Pittman, 1982), and material and monetary gain (James, 1890; Jellison \& Gentry, 1978). We do not know the relative importance of these motives or the conditions under which different motives become dominant.

Whom do people seek to impress? The hard core of the research program places virtually no constraints on the types of social identities people claim or on the motives for claiming these identities. It also places no constraints on the types of audiences people seek to impress or on the importance people attach to impressing different audiences. Some theorists may choose to emphasize impression management aimed at external audiences (in- dividuals who are present in the immediate social situation). Others may choose to emphasize impression management aimed at both external audiences and internal or imaginary ones (significant others whose perspective the actor adopts to evaluate his or her own conduct).

No integrative theory specifies when impression management will be targeted at internal versus external audiences. Much depends on personality variables (e.g., social anxiety, private and public self-consciousness, self-monitoring) and situational factors (e.g., the presence of an external audience, audience status and values, cues that promote private or public self-awareness).

What behavioral tactics do people employ to achieve desired identities? Here again, the hard core provides no answer. There is an indeterminate number of paths people can pursue to achieve identity goals (e.g., to get someone to like you, you may conform to their opinions, flatter them, or boast about your accomplishments). To predict which impression management tactics people will employ, we need detailed knowledge of the goals they seek, the alternative means they perceive to attaining these goals, and their perceptions of the relative feasibility of the different means (cf. Schneider, 1981).

How effective are people as impression managers? Acceptance of the hard core of the research program does not imply that people always select the "best" or "optimal" behavioral tactics for impressing others. Although some writers have made strong assumptions about people's competence as impression managers (e.g., Alexander \& Rudd, 1981), such assumptions are not integral to the research program. It is perfectly conceivable, for example, that people are motivated to create certain impressions on others, but often miscalculate the social impact of their behavior. There may well be errors and biases in impression management that are intimately related to errors and biases that have been documented in attribution and social inference processes. There may also be large individual differences in impression management skills or social competence (Schlenker \& Leary, 1982).

How aware are people of engaging in impression management? Although some 
writers have used the term impression management to refer to the self-conscious deception of others (e.g., Gaes, Kalle, \& Tedeschi, 1978), there is no compelling psychological reason why impression management must be either duplicitous or under conscious control. Impression management may be the product of highly overlearned habits or scripts, the original functions of which people have long forgotten (Jones \& Pittman, 1982; Schlenker, 1980). People may also sincerely believe in the identities they project to others (Baumeister, 1982).

\section{What Then is Impression Management?}

The previous discussion indicates the many directions in which theorists can articulate and refine the image of human nature at the hard core of the impression management research program. This absence of formal theoretical structure means that there are no real constraints on advocates who wish to interpret findings in terms of the impression management perspective. As it now stands, the research program assumes only that people attempt to create desired impressions on others. It is difficult to imagine what evidence could be inconsistent with such a vague formulation. What behavior is not open to construal as a sincere or insincere, successful or unsuccessful attempt to create an unspecified impression on a real or imaginary audience? The impression management research program is most appropriately viewed not as a theory, but as a metatheoretical framework within which one can formulate and seek answers to questions on the causes and consequences of human social behavior;

\section{Distinguishing Impression Management From Intrapsychic Explanations}

Attempts to assess the explanatory power of the impression management research program have focused on distinguishing impression management explanations from rival intrapsychic accounts of experimental findings. These between-theory confrontations have included debates over (a) cognitive dissonance versus impression management explanations of attitude moderation effects in forced compliance experiments (Schlenker, 1982; Tedeschi \& Rosenfeld, 1981), (b) per- suasive arguments versus impression management explanations of group-induced attitude polarization (Myers \& Lamm, 1976), (c) reactance versus impression management explanations of how people respond to threats to their behavioral freedom (Baer et al., 1980), (d) ego-defensive versus impression management explanations of self-serving attribution biases (Weary \& Arkin, 1981), (e) equity versus impression management explanations of resource allocation decisions (Reis, 1981). The common theme running through impression management explanations is that experimental manipulations used in the above research paradigms influence behavior by affecting subjects' perceptions of the social identity implications of response options. Subjects respond to dependent measures in ways designed to claim valued social identities. The common theme running through intrapsychic explanations is that these same experimental manipulations influence behavior by affecting subjects' perceptions of the personal appropriateness or correctness of available response options. Subjects respond to dependent measures in ways designed to achieve hypothetical, internal, cognitive or motivational states-states often defined in terms of equilibrium restoration (e.g., reduction of dissonance, reactance, inequity distress, or threats to self-esteem).

In this section, we examine the general methodological strategies (which cut across specific between-theory controversies) that investigators have used to distinguish between impression management and intrapsychic explanations. Each strategy is based on distinct sets of restrictive assumptions concerning the processes identified by the two competing classes of theory. However, such research does not distinguish between impression management and intrapsychic explanations in general. It distinguishes only between artificially restricted versions of the impression manage. ment and intrapsychic positions. Two fundamental obstacles exist to assessing the com. parative 'validity of impression managemen and intrapsychic explanations: (a) the openendedness of the impression managemen research program (a determined defender 0 the hard core can explain-post hoc-any pattern of results), and (b) the equal open endedness of rival intrapsychic formulation 
(positions that, with the aid of empirically defensible auxiliary assumptions, can mimic the predictions of impression management theories).

\section{Public-Private Manipulations}

The most obvious means of distinguishing between the two classes of explanation is to assume that impression management occurs only when subjects believe that other people can observe their behavior, whereas intrapsychic processes occur independently of subjects' beliefs on this issue. Distinguishing rival theoretical accounts for an experimental effect becomes a straightforward matter of manipulating the degree to which subjects believe their behavior is under public scrutiny. The appeal of this methodological strategy is reflected in its widespread use. Investigators have used public-private manipulations to resolve between-theory debates in several empirical arenas, including forced compliance (e.g., Tedeschi \& Rosenfeld, 1981), reward allocation decisions (e.g., Morse, Gruzen, \& Reis, 1976), reactance (e.g., Baer et al., 1980), and self-serving attribution biases (e.g., Weary $\&$ Arkin, 1981). Here we draw from research on reactance to illustrate the logic of this strategy.

Brehm's (1966) reactance theory assumes that people become motivationally aroused whenever they think their freedom to act in a particular way has been eliminated or threatened with elimination. This motivational arousal-known as psychological reactance-can vary in intensity as a function of a number of independent variables (e.g., the importance of the freedom) and is hypothesized to move people to restore their freedom by exercising the threatened option. By contrast, impression management theorists (e.g., Baer et al., 1980; Heilman \& Toffler, 1976) argue that individuals' responses to threats to behavioral freedom arise not from reactance but from their desire to project an image of autonomy to others-although theorists differ with respect to who these others are (e.g., the person responsible for the diminution of personal freedom versus any witness to the event).

Baer et al. (1980) contrasted the reactance and impression management explanations of the evidence by employing two public-private manipulations. The independent variables in their study were (a) whether subjects received a low-threat or high-threat persuasive communication, (b) whether subjects had previously had an opportunity to exercise their freedom (by expressing a position contrary to that advocated in the communication) and whether this prior opportunity was public or private, and (c) whether subjects expressed their postcommunication attitudes on the issue in question publicly or privately. If subjects were responding solely to an internal state of reactance aroused by the threat to their freedom to hold their own opinion on the experimental issue, it should not have mattered whether the prior opportunity to assert their freedom was public or private, or whether their postcommunication attitudes were expressed publicly or privately. Subjects should have exhibited greater attitude change away from the advocated position in response to the high-threat message, and should have done so to a lesser degree when they had had a prior opportunity to exercise their freedom. However, if impression management concerns were paramount, then subjects' responses to the high- and low-threat messages should have depended on the degree to which their earlier assertion of freedom and their postcommunication expression of attitude were public or private. Reactance-type effects should have occurred only when the threatened behavior was public and subjects had not previously exercised their freedom in public.

Baer et al. (1980) found that evidence of reactance was confined to public attitude expression and that only when prior exercise of freedom was public did it mitigate attitude change. They regarded these findings as being "consistent with a self-presentation theory of psychological reactance" (Baer et al., 1980, p. 421). However, Wright and Brehm (1982, p. 612) argued that Baer et al.'s findings are also consistent with traditional reactance theory. Exactly how Wright and Brehm reached this conclusion deserves mention, for the modifications they make to reactance theory to permit it to mimic impression management predictions can-mutatis mutandis-be applied to any intrapsychic theory. The key concession Wright and Brehm must make is 
that "interpersonal processes can affect reactance arousal and expression" (p. 617). But they do not conclude from this that reactance theory can by subsumed within an impression management explanation; indeed, they conclude the opposite - that the impression management explanation of reactance effects is subsumable within reactance theory. To achieve this subordination, they have to introduce two assumptions that are not part of the original reactance formulation, namely, (a) that relatively direct attacks on one's initial attitudinal position by someone with whom one anticipates interaction may constitute a much stronger threat to attitudinal freedom than do written attacks from a person one never expects to meet, and (b) that public expressions of opposition may not only restore the specific freedom threatened, but also may deter influence agents from future attacks on important freedoms. Clearly, Wright and Brehm wish to treat interpersonal factors as variables that moderate the fundamental processes of reactance arousal and expression, rather than as a class of factors that produce effects analogous to traditional reactance phenomena but through a distinctive set of mediating processes. There is little basis, though, for preferring the modified version of reactance theory over an impression management account, when the modified theory is compelled to adopt ad hoc assumptions in order to accommodate evidence cited in support of the impression management position.

Despite their intuitive appeal, public-private manipulations do not provide an effective means of distinguishing between competing reactance and impression management explanations for the evidence, and we submit that a similar conclusion would emerge from consideration of research using public-private manipulations in fields other than reactions to loss of freedom. The grounds for our generalized skepticism are twofold: (a) Publicprivate manipulations can always be reasonably supposed to have intrapsychic effects (e.g., the arousal-inducing properties of the presence of an audience-Borden, 1980; $\mathrm{Za}$ jonc, 1980; the power of an audience to induce objective self-awareness-Wicklund, 1980; the commitment-increasing effects of public behavior-Kiesler, 1971; the effects of expected interaction on amount and types of
thought-Tetlock, 1983). Intrapsychic theories can thus draw on a rich pool of auxiliary hypotheses for explaining why people in public behave differently from people in private. (b) Not all impression management explanations require that experimental findings (e.g., reactance effects, dissonance effects) occur only in public. Some impression management theories posit that people try to impress internalized audiences-a process that could occur under conditions of total experimental anonymity.

\section{Manipulations of Audience Beliefs or Values}

A second strategy for distinguishing the two classes of explanation is to manipulate the perceived beliefs or values of the audience with whom subjects expect to interact. The reasoning here is that an actor's behavior should, according to impression management theories, be responsive to such variations, whereas intrapsychic theories would lead one to expect effects that do not vary as a function of such audience attributes. For example, proponents of cognitive dissonance theory should regard as irrelevant subjects' perceptions of the degree to which observers view the subjects as freely choosing to perform a counterattitudinal behavior. Because dissonance arousal and reduction is an intrapsychic process arising from the subjects' awarenessin this case-of inconsistency between their attitudes and a freely chosen behavior, what an audience is thought by the subject to believe should have no impact on attitude change. On the other hand, the audience's perceived beliefs regarding subjects' decision freedom should be a crucial variable from the perspective of those who advocate an impression management explanation of forced compliance phenomena because their argument is that attitude change reflects the subjects' desire to appear consistent in the eyes of others. Thus, subjects in a standard highchoice condition who believe that observers do not regard them as having freely chosen to perform the counterattitudinal behavior have no need to manage the appearance of consistency, and should therefore not exhibit attitude change.

Just such a finding was reported by Riess and Schlenker (1977). However, this finding 
need not cause much embarrassment to the committed dissonance theorist, who could argue that Riess and Schlenker's manipulation of perceived audience beliefs had the unintended consequence of making responsibility denial a more salient or plausible mode of dissonance reduction for high-choice subjects who were led to believe that the audience saw them as having low choice. When you are told that others do not view you as having acted freely, denying responsibility for the consequences of your action may become an effective means of reducing dissonance. Moreover, there are independent theoretical grounds for assuming that the manipulation of audience beliefs used by Riess and Schlenker would influence subjects' choice of mode of dissonance reduction. Wyer and Hartwick (1980) have argued that when people are asked to make attitudinal judgments, they do not carry out an exhaustive search of long-term memory for all relevant information. Rather, they base their judgments on that relatively small subset of stored information that happens to be easily retrievable or available. If this argument is correct - and Wyer and Hartwick present considerable evidence to support it - then one could reasonably contend that (a) perceptions of our own responsibility for counterattitudinal behavior are known to be important in generating attitude change following forced compliance (cf. Wicklund \& Brehm, 1976), (b) individuals will scan their memories for information relevant to judgments of their own responsibility for counterattitudinal behavior when asked to report their postbehavior attitudes, and (c) individuals who have recently learned that others do not regard them as responsible for the behavior are more likely to use this information in resolving any discomfort about having behaved counterattitudinally than are those who have not been given this information. In short, Riess and Schlenker's (1977) manipulation of audience beliefs may have primed subjects to engage in responsibility denial as a means of reducing cognitive dissonance.

Priming interpretations are possible for other studies that rely on manipulations of audience beliefs and values. For instance, several experiments suggest that the rules of distributive justice that subjects use in making reward allocation decisions depend on the type of audience that subjects believe will learn of their decisions (e.g., Reis, 1981). Subjects tend to use an equity rule in the presence of audiences perceived to value competitiveness or productivity. Subjects tend to use an equality rule in the presence of audiences perceived to value egalitarianism or interpersonal harmony. These results have been taken as support for an impression management analysis of distributive justice decisions and as problematic for intrapsychic formulations that emphasize internalized standards, such as equity theory. Again, however, we cannot rule out possible cognitive mediators. People may internalize a number of rules of distributive justice (equity, equality, need, etc.) that are activated in different contexts (cf. Deutsch, 1975; Greenberg, 1983). Different audiences may prime different standards. Although methodologically convenient, no strong theoretical justification exists for assuming that variations in perceived audience attributes do not influence intrapsychic processes such as dissonance reduction or choice of reward allocation rules. If anything, we see growing support for the opposite conclusion. Often unsure of their own beliefs and values, people may simply adopt the most cognitively available response in the immediate situation (Nisbett \& Ross, 1980).

\section{Contextual Manipulations}

A third strategy for distinguishing between impression management and intrapsychic explanations has been to manipulate the stimulus information presented to subjects in ways that influence the processes specified by one class of explanation, but not the processes specified by the other. Examples of this strategy abound in the literature on group-induced polarization of attitudes: the tendency for group discussion to strengthen the initially dominant attitude among members of the group. In this realm the intrapsychic explanation is represented by persuasive arguments theory (e.g., Vinokur \& Burnstein, 1978), whereas the impression management explanation is represented by a variant of social comparison theory (e.g., Jellison \& Arkin, 1977; Sanders \& Baron, 1977).

Persuasive arguments theory holds the ar- 
guments that emerge in the course of group discussion on a given issue tend to favor the alternative generally preferred by group members, and that because it is very unlikely that any individual group member will have considered all these arguments, some of them will have persuasive impact. According to this explanation, then, the influence of group discussion on individual and collective attitudes stems from what is said and thought in the course of the discussion, and not from mere exposure to the positions adopted by other group members. Impression management explanations of group polarization, by contrast, hold that the crucial property of group discussion is that in the course of discussion each individual learns the positions of other members on the issue in question; impression management explanations attach significance to the arguments espoused by group members only insofar as these arguments reveal where group members stand on the issue. ${ }^{1}$ The motivating aspect of learning others' positions on the issue stems from the assumption that individuals value positions on the issue that are more extreme than their own, and yet do not initially adopt these extreme, ideal positions for fear of being regarded as deviant. Thus the discovery that other group members are closer in position to the ideal than was imagined to be the case should either release individuals to act out their private inclinations more fully (Pruitt, 1971) or to motivate them to compete with other group members for positions approaching the ideal because of a desire to keep one step ahead of the average (Jellison \& Davis, 1973; Myers, 1978).

Burnstein and Vinokur (1977) have been forceful advocates of the view that persuasive arguments theory can fully explain group polarization effects without the assistance of impression management theory (see also Vinokur, Trope, \& Burnstein, 1975). They contend that "social comparison is neither a necessary nor sufficient condition for polarization" (Burnstein \& Vinokur, 1977, p. 315). In response, advocates of the impression management perspective have sought evidence for social comparison processes that would not be open to reinterpretation in terms of persuasive arguments theory. This search has focused on experimental manipulations that (a) provide subjects with information on group members' positions on issues, and (b) do not affect the availability of persuasive arguments in favor of one or another position on the issues.

Several experiments seemingly satisfy these requirements-experiments which inform subjects of others' positions but not of the arguments that others advance to support those positions (e.g., Baron \& Roper, 1976). Lamm and Myers's (1976) careful review of these studies indicates that mere knowledge is, indeed, sufficient to produce polarization. However, advocates of persuasive arguments theory have been unpersuaded. They have maintained that such effects are completely consistent with their perspective:

Knowledge that others' choices are discrepant from one's own may induce the person to reconstruct a line of reasoning that he thinks could have produced such choices. This is to say, knowing that others have chosen differently stimulates the person to generate arguments which could explain (and thus would support) their choices. (Burnstein, Vinokur, \& Trope, 1973, p. 244)

Persuasive arguments theorists are willing, moreover, to extend this reasoning to virtually any judgment task - even to "argument-poor" settings such as estimating the amount of light movement in the autokinetic task (Baron \& Roper, 1976). In these settings, it is still possible to imagine argumentation or cognitive activity that may be triggered by mere knowledge of others' choices and that may mediate polarization effects (see Burnstein \& Vinokur, 1977). Conclusive evidence for the social-comparison/impression-management perspective has thus remained elusive.

Another empirical domain in which researchers have used contextual manipulations to tease apart rival theoretical accounts is the forced compliance paradigm-in particular, work on the relationship between the amount of payment to engage in counterattitudinal behavior and the amount of attitude change in the direction of that behavior. A large and contradictory body of findings exists on this

\footnotetext{
${ }^{1}$ Impression management explanations need not take so strong a stand on the irrelevance of the content of arguments exchanged in group discussion. There is good reason for suspecting that the arguments subjects hear on a topic influence their perceptions of the social desirability of different positions on that topic.
} 
topic. Sometimes investigators find support for the cognitive dissonance prediction on an inverse relationship: smaller payments leading to less justification for the counterattitudinal behavior, and greater dissonance and greater attitude change. Sometimes investigators find support for reinforcement theory: larger payments serving as greater incentives for counterattitudinal behavior and consequently leading to greater attitude change. In his thorough review of this literature, Schlenker (1982) noted that neither perspective can explain all the evidence, and proposed an identity-analytic explanation that he maintains is better equipped for the task. According to this analysis, instead of asking how payments affect intrapsychic processes such as cognitive inconsistency or simple reinforcement, one should ask: How does the social meaning of the payment affect the identities subjects are trying to claim in a given experimental setting?

Schlenker, Forsyth, Leary, and Miller (1980) reported three experiments that demonstrate that the social meaning of payment does moderate the relationship between amount of payment and attitude change in the forced compliance paradigm. For instance, in Experiment 3 they found that when payments appeared illegitimate (e.g., bribery for performing an unsavory act), people became concerned with appearing to be the type of person who could not be bought. The greater the payment, the greater this identity threat, and the more likely subjects were to change their attitudes (hence, a direct relationship). In Experiment 1, they found that when the legitimacy of payment was not in question (e.g., remuneration for helping to develop new psychological measures), the payment affected people's perception of their responsibility for the counterattitudinal behavior. The larger the payment, the less responsible subjects felt and the less need they felt to justify their counterattitudinal behavior (hence, an inverse relationship).

Schlenker et al. (1980) advanced our understanding of a long-standing riddle in experimental social psychology. The studies do not, however, eliminate all intrapsychic explanations for the evidence. As Schlenker concedes, contemporary versions of dissonance theory (in particular, the responsibility- for-negative-consequences-that-threaten-theself version-Greenwald \& Ronis, 1978) can readily explain the evidence. It is highly dissonant as well as socially awkward to acknowledge that one lacks the moral conviction to resist a bribe.

There is a general lesson to be drawn from the empirical controversies reviewed in this section. Impression management and intrapsychic processes are naturally interwoven and attempts to identify stimulus manipulations that only affect one set of processes will inevitably be unsuccessful. Experimental manipulations intended to influence intrapsychic processes such as the generation of persuasive arguments, reactance, dissonance, or inequity distress cannot help but influence the social identity implications of response options available to subjects. Good judgment, honesty, autonomy, and faimess are not only characteristics that we value in judging ourselves; they are valued by the social groups to which we belong. Conversely, experimental manipulations intended to influence only the social identity implications of response options available to subjects inevitably influence intrapsychic responses. No neat, nonarbitrary line divides the intrapsychic from the social.

\section{Sincerity of Response Manipulations}

A fourth strategy for distinguishing between impression management and intrapsychic explanations has been to focus on the sincerity of responses motivated by each type of process. Theorists have argued that responses motivated by impression management concerns are "uninternalized, temporary, feigned" (Tedeschi \& Rosenfeld, 1981, p. 158 ), at least in situations where it is unlikely that well-ingrained habits of impression management are elicited. In contrast, responses that are the output of intrapsychic processes are-by definition-internalized, and should be experienced by subjects as genuine. It follows that the relative sincerity of responses should be a means of distinguishing the two types of explanation, given that one has a procedure for determining whether responses are feigned or sincere.

Such a procedure may be provided by the bogus pipeline (BPL), which Jones and Sigall (1971) developed as a method of attitude measurement that minimizes dissimulation 
by respondents. The central feature of the BPL procedure is convincing subjects that electrophysiological equipment used by the experimenter provides accurate readings of their feelings. From an impression management perspective, the subject is thereby placed in the dilemma of either telling the truth and relinquishing the impression management benefits that would accrue from feigned responses, or being perceived as a liar as well as giving up impression management benefits. Placed in such a dilemma - it is argued - the typical subject minimizes costs and opts for the truthful alternative. Impression management theorists would thus anticipate systematic variation in subjects' responses between BPL and no-BPL conditions. From the perspective of intrapsychic theorists, on the other hand, the subjects' responses are genuine and should therefore not vary as a function of a procedure such as the BPL.

The most extensive application of the BPL has been in forced compliance research (for a review, see Tedeschi \& Rosenfeld, 1981). The typical finding in these studies has been that attitude change in the direction of the counterattitudinal behavior is obtained when postbehavior attitudes are assessed by standard pencil-and-paper techniques, but is not obtained when subjects believe that their responses are being monitored by the BPL device. For instance, Gaes et al. (1978) induced subjects to write antitoothbrushing essays that would allegedly be read by impressionable junior high school students. The postbehavior attitudes of one half of the subjects were assessed on standard paper-andpencil attitude scales; the remaining one half responded to the same questions while connected to the BPL. Gaes et al. found that subjects shifted toward a more antitoothbrushing position when they responded to the paper-and-pencil scales, but not when they responded to the BPL. Gaes et al. also found that subjects in the paper-and-pencil conditions only shifted their attitudes when they felt publicly identified with the antitoothbrushing speech and not when their anonymity was guaranteed. In brief, the pattern of findings suggested that the attitude change effect was feigned by subjects for public consumption.
However, good reasons exist for caution in drawing strong theoretical conclusions from such studies. First, as noted earlier, impression management need not involve self-conscious deception of others. People may truly believe opinions that serve to enhance their social images. The BPL tests only a very restricted, Machiavellian version of impression management theory. Second, intrapsychic theories can postulate that people engage in selfdeception in which they simultaneously hold contradictory beliefs and actively suppress one of the beliefs out of awareness (e.g., Sackeim, 1981). The BPL may reduce attitude change in the forced compliance paradigm by interfering with intrapsychically motivated self-deception (cf. Greenwald, 1980). Third, the attenuation of attitude change under BPL conditions may be artifactual. For instance, Scheier and Carver (1980) proposed that the BPL reduces attitude change by directing subjects' attention to their initial attitudes, thereby decreasing the likelihood that subjects will employ attitude change as a method of dissonance reduction. Cialdini et al. (1981) have argued that the BPL encourages subjects to misattribute dissonance-produced arousal to plausible, alternative causes (e.g., anxiety about the equipment). Arkin (1981) contended that the BPL provides subjects with demand cues, in that the use of a machine to record internal states suggests to subjects that the experimenter is seeking socially undesirable responses. A nondemand version of the Arkin argument would emphasize the power of the BPL to induce a biased scanning of memory for socially undesirable attitudes.

Advocates of the BPL have taken issue with most of these criticisms. Some of the defenses are quite convincing (e.g., Paulhus, 1982; Tedeschi \& Rosenfeld, 1981). Such defenses notwithstanding, we are pessimistic about the between-theory testing potential of the BPL. Too many theoretical and methodological escape clauses exist. The complexity and unusualness of the BPL procedures make it inevitable that those who wish to argue for intrapsychic explanations of such effects will be able to find some feature of the BPL that accounts for inhibition of attitude change in terms other than elimination of impression management. 


\section{Social Identity Implications of Behavior}

A fifth strategy for distinguishing between the two classes of explanation has been to assess the social identity implications of subjects' behavior in experimental settings. Some investigators have assumed that individuals who are motivated by impression management concerns always behave in a fashion that creates favorable (even optimal) impressions on others, whereas this is not the case for individuals whose behavior reflects the operation of intrapsychic processes.

Alexander and Knight (1971) adopted this strategy in an interpersonal simulation of a well-known study by Carlsmith, Collins, and Helmreich (1966). Carlsmith et al. offered subjects small or large payments to inform others that a boring experimental task was interesting. Some subjects performed this deception in a face-to-face encounter with another person, and others wrote an essay describing the experimental task as interesting. The results indicated an inverse relationship between amount of payment and attitude change in the face-to-face condition, and a direct relationship between these two variables in the essay-writing condition. Alexander and Knight presented observer subjects with detailed reenactments of how a hypothetical subject had reacted in various conditions of the original study. Observers evaluated the subject most positively when the subject exhibited responses that conformed to the mean patterns of attitude change reported in the Carlsmith et al. study. They also found that observers were mainly concerned with the honesty of the subject in the face-to-face condition (Is this person willing to sell out his or her convictions?) and with the competence of the subject in the essay-writing condition (Can this person construct an effective persuasive appeal?). Alexander and Knight argued that the original experimental manipulations influenced behavior by changing the social identity implications of response options in complex and qualitative ways.

Interpersonal simulations of this type provide useful information on the normative significance of behavior in experimental settings (see also Alexander \& Rudd, 1981; Tetlock, 1980). However, data from simula- tions shed limited light on the relative viability of impression management versus intrapsychic explanations for experimental findings. First, failure to find that subjects behaved in a socially desirable way does not rule out an impression management explanation for a given finding. Subjects may have tried to create a good impression, but incorrectly judged which responses would have the desired effect. Second, finding that subjects behaved in a socially desirable way does not rule out an intrapsychic explanation. Responses produced by intrapsychic processes may also evoke substantial approval from observers. Observers presumably share the aversion that actual subjects feel to such intrapsychic states as dissonance, inequity or reactance, and may even vicariously experience these states (cf. Regan \& Totten, 1975). It should not be surprising then if observers evaluate most positively those subjects who give responses that make psychological sense (reduce intrapsychic distress).

\section{Personality Variables}

Finally, a sixth methodological strategy for distinguishing between impression management and intrapsychic explanations has focused on personality variables. Investigators have tried to identify personality variables that the two classes of theory suggest will be differentially associated with individual differences among subjects in the magnitude of experimental effects.

One personality variable that has attracted considerable attention during the last decade is that of self-monitoring (Snyder, 1979). According to Snyder, high self-monitors are persons who "shrewdly and pragmatically tailor their social behavior to fit situational and interpersonal specifications of appropriateness" (Snyder \& Campbell, 1982, p. 186). Low self-monitors, by contrast, are "principled beings who value congruence between their actions in social situations and relevant underlying attitudes, feelings and dispositions" (p. 187). Snyder's (1979) review of the literature reveals support for many predicted differences between low and high scorers on the self-monitoring scale. In comparison to low scorers, high scorers are more likely to 
adapt their behavior to the normative requirements of particular situations, more likely to seek out information on what others consider appropriate behavior, and less likely to rely on internalized standards as guides to behavior. Overall, the behavior of high selfmonitors appears to be primarily under the control of impression management concerns; the behavior of low self-monitors, primarily under the control of intrapsychic processes.

This evidence suggests that the self-monitoring variable should be useful in assessing the comparative validity of impression management and intrapsychic explanations for experimental findings. Those effects mediated by impression management processes should occur much more strongly among high selfmonitors; those effects mediated by intrapsychic processes should occur much more strongly among low self-monitors. For example, in applying the self-monitoring construct to the forced compliance situation, one could argue that an impression management explanation leads to the prediction that high self-monitors, attuned as they are to projecting desired social images, would be more concerned than would low self-monitors with appearing consistent, and would therefore exhibit greater attitude change (cf. Tedeschi, Schlenker, \& Bonoma, 1971). Likewise, one could argue that low self-monitors, who supposedly attach high value to maintaining consistency between their thoughts and actions, should-according to dissonance theory - be especially prone to experience distress when subtly pressured into behaving counterattitudinally, and should therefore exhibit greater attitude change. Impression management theory and dissonance theory thus appear to give rise to different predictions concerning the type of individual likely to exhibit attitude change following forced compliance.

Research on self-monitoring and forced compliance has found that low self-monitors exhibit greater attitude change (Paulhus, 1982; Snyder \& Tanke, 1976), apparently in support of the dissonance explanation. Such support is by no means unequivocal, however, because concern with acceptance by others is not the only distinctive attribute of the high selfmonitor. Personality traits do not occur in isolation; they are intercorrelated. Scores on the self-monitoring scale (and its component subscales) may be related to many other individual difference variables, each with somewhat different implications for the between-theory debate (e.g., self-esteem, social anxiety, need of approval; Briggs, Cheek, \& Buss, 1980). It is also possible that high and low self-monitors differ not so much in their concern for impression management, but in the types of impressions they seek to create on others. Low scorers may be much more concerned than are high scorers with projecting an honest and principled image (a plausible speculation in view of the item content of the self-monitoring scale). In this case, the finding of less attitude change among high self-monitors is best interpreted in terms of the different impression management goals of high and low self-monitors and has little relevance to cognitive dissonance theory.

These interpretive ambiguities underscore a fundamental problem: Self-report measures of personality constructs-even those that have been subject to extensive research-are invariably open to alternative interpretations (cf. Fiske, 1971). We see, moreover, an element of irony in turning to self-report measures of personality traits in order to distinguish impression management and intrapsychic explanations of experimental findings because competing impression management and intrapsychic explanations also exist for how people respond to self-report personality scales (e.g., Johnson, 1981). A classic example is the debate over the social desirability versus personal adjustment interpretations of the first or alpha factor of the Minnesota Multiphasic Personality Inventory (MMPI; Block, 1965). Do self-report tests measure intrapsychic dispositions, claims to social identities, or some combination of these influences?

Bem and associates (Bem \& Funder, 1978; Funder, 1982) have developed an alternative approach to using individual difference variables for testing competing theories-an approach that takes many personality variables into account simultaneously and does not depend on self-report responses to questionnaires. The most distinctive aspect of the Bem procedure (known as template matching) is its interactionist focus. The objective is to assess on a common set of dimensions the personalities of both subjects and experimen- 
tal situations. Observers rate the degree to which trait dimensions characterize (a) individual subjects and (b) the ideal type of individual who is most likely to display a given pattern of behavior in the situation in question. The guiding assumption is that an individual is likely to behave in a given way to the degree his or her personality template closely matches that of the behavior template.

The template-matching approach can be readily adapted for testing rival impression management and intrapsychic theories. For instance, Bem and Funder (1978) used this procedure to compare three well-known theories of how attitude change results from forced compliance: cognitive dissonance, selfperception, and impression management theory. The first step was to devise an individual template for each theory by having advocates of the competing formulations independently select California Q-Sort items that would be expected by each theory to characterize individuals who exhibit posttest attitude change following freely chosen counterattitudinal behavior. They also obtained Q-Sort ratings of each of their subjects from the subjects' acquaintances. The match between a subject's Q-Sort ratings and each of the three theoryderived templates was then correlated, across subjects, with attitude-change scores. Clearly, the theory that best predicts individual variation in attitude change should be the one with the highest correlation between templatesimilarity scores and attitude-change scores. In this case, impression management theory emerged as the winner, followed by selfperception theory and cognitive dissonance theory. We should not, however, place too much trust in any one study. Funder (1982) reported a quite different pattern of correlations between template-similarity and attitude-change scores in an expanded replication of the Bem and Funder study.

Despite these problems of replicability, template matching is a promising methodological and theoretical development. However, we doubt that template-matching evidence will ever be conclusive in resolving debates between advocates of intrapsychic and impression management explanations. Problems of multicollinearity among theoryderived templates already exist (cf. Funder, 1982). Competing theories can easily mimic each other's predictions by simply incorporating new individual difference variables in their templates-new variables that share substantial variance with those in the prediction formulas of the other side. For instance, the range of individual difference variables relevant to the impression management perspective is enormous (e.g., variations in concern for how one appears to others, those whom one seeks to impress, the types of impressions one seeks to create on these audiences, skill at creating desired impressions, social anxiety and self-esteem, willingness to deceive others). An equally lengthy and partly overlapping list of individual difference variables could be generated for intrapsychic theories.

\section{An Alternative to Between- Theory Confrontation}

We have argued that neither side emerges as a clear winner of the numerous empirical confrontations between intrapsychic and impression management explanations. ${ }^{2}$ A more profitable strategy is to abandon the search for crucial experiments and to focus on clarifying the points of similarity and dissimilarity between rival intrapsychic and impression management theories.

\footnotetext{
${ }^{2}$ A seventh methodological strategy for distinguishing the two classes of explanation-not mentioned previously-should be noted. Intrapsychic formulations such as cognitive dissonance and reactance theories assign a key mediating role to arousal in producing behavioral effects. Empirical support for this theoretical position does, moreover, exist. A series of ingenious misattribution experiments suggest that arousal is, indeed, a critical mediator of certain attitude change effects observed in the forced-compliance paradigm (for a review, see Fazio \& Cooper, 1983). Although such evidence casts doubt on the viability of the self-perception explanation of attitude change in forced-compliance experiments, the relevance of such evidence to attempts to distinguish impression management and cognitive dissonance explanations is much more questionable. As noted earlier, advocates of impression management theories often assign a key role to aversive arousal states (e.g., embarrassment) in motivating behavior. Because independent evidence exists that threats to social images produce aversive arousal states (Schlenker, 1980) and that forced-compliance experiments create threats to social images (Schlenker, 1980; Tedeschi \& Rosenfeld, 1981), advocates of impression management explanations are well placed to assimilate evidence on the mediating role of arousal in forced-compliance experiments.
} 
Our position on the futility of seeking decisive empirical confrontations can be placed in a broader philosophical context. McGuire (1983, p. 7) noted that social psychology has traditionally been dominated by a logical empiricist epistemology which assumes that our field progresses by our having theories from which we derive hypotheses, which are then put in jeopardy by empirical tests. He argued that the shortcomings of this viewpoint are increasingly distorting the way we conduct our work and proposes an alternative constructivist epistemology. Departing radically from the logical empiricist tenets that some theories are right and others wrong, and that the function of the empirical work is to test which of several opposed theories is right, constructivism posits that each of the several competitor theories is right and that "empirical work is conducted to reveal the conditions under which the complementary theories obtain" (McGuire, 1983, p. 7).

In this spirit, we do not doubt that there are situations in which impression management processes (construed narrowly) are of primary importance and others in which intrapsychic processes (construed narrowly) are of primary importance. The impression management and intrapsychic perspectives are examples of what McGuire (1983, p. 35) terms guiding-idea theories, that is, "partial views of the person, each of which exploits the provocative implications of a selective depiction of human nature." The tension between the guiding-idea theories underlying intrapsychic and impression management explanations is one of the most fundamental in social and personality psychology. The innerouter metaphor, the core of the distinction, appears in a variety of contexts, such as personality assessment (for reviews, see Allport, 1943; Hogan, 1982) and experimental studies of ego involvement (for a review, see Greenwald, 1982).

The enduring concern with the innerouter distinction underscores its theoretical importance. However, the failure to resolve the long-standing controversy over the primacy of inner and outer sources of influence suggests the intractability of the debate. We have strong reservations about portraying research efforts as means of identifying the "true" theory. Serious logical and methe ological obstacles exist to distinguishing ! tween impression management and intrap: chic explanations. Although intuitively a pealing, the dichotomy between the $t v$ categories of theory is arbitrary. Each $p \epsilon$ spective has a seemingly unlimited capaci to mimic the predictions of the other.

The theoretical problem needs to be refo mulated. Impression management and intr psychic explanations should be viewed not mutually exclusive oppositions, but as speci cases of an integrative theoretical framewo. that focuses on basic processes common both categories of explanation. Potential it tegrative frameworks have, moreover, alreac begun to emerge in the literature, includir recent applications of cybernetic control the ory to behavioral self-regulation (Carver Scheier, 1981), Greenwald's (1982) ego tas analysis, and Schlenker's (1982) identity-ar. alytic theory of social conduct. Althoug these integrative frameworks are not inte1 changeable, they do share crucial features All assume that people are motivated t maintain acceptable levels of consistency be tween their conduct and standards of appro priate behavior. In cybernetic control terms comparison of behavior with an evoked stan dard sets in motion a classic test-operatetest-exit (TOTE) sequence. Recognition $o$ discrepancy between current behavior ano the evoked standard triggers attempts to reduce the discrepancy to a tolerable level. The integrative frameworks also agree that peopl $\epsilon$ monitor their behavior with respect to both internal and external behavioral standards. Internal standards-the traditional focus of intrapsychic theories-are those to which the individual subscribes. They represent critical values on important dimensions along which individuals evaluate themselves (standards of self-identity). External standards-the traditional focus of impression management theories-are those to which actually or imaginatively present others are perceived as subscribing. External standards represent critical values on important dimensions along which the individual is evaluated by others (standards of public identity).

These integrative frameworks highlight a fundamental similarity between-intrapsychic 
and impression management explanations. Both classes of explanation assume that people rely on behavioral standards (albeit different types of standards) to monitor and evaluate their own conduct. Most important, however, the integrative frameworks suggest an alternative to the adversarial approach to theory development-an alternative that downplays the search for crucial experimental tests and emphasizes in its place research objectives that are both more attainable and more likely to stimulate cumulative empirical work. Major theoretical challenges become

1. Documenting the content and functional properties of behavioral standards. Rather than devoting effort to the ultimately definitional issue of whether a given standard is truly intrapsychic or social, researchers would do well to develop a viable empirical taxonomy of behavioral standards. The classification system should take into account the content of behavioral standards (What dimensions of personal or social identity are subject to evaluation-one's fairness, independence, competence, etc.?) and the functional properties of standards (To what extent does this standard operate only in public? Is the standard highly sensitive to variations in audience beliefs and values? Does the standard lead to responses that people disavow when they think others can detect deception?). The simple internal-external dichotomy may seriously oversimplify the variety of behavioral standards activated in everyday life (cf. Greenwald \& Breckler, in press).

2. Generating and testing person-situation interaction predictions. People vary in the types of behavioral standards they habitually use to monitor their own conduct (Carver \& Scheier, 1981; Hogan, 1982). Situations vary in the types of behavioral standards they make salient (Greenwald, 1982). All of the integrative frameworks alluded to earlier imply that situations that activate a given behavioral standard have their greatest impact on persons who are predisposed to rely on that standard (Carver \& Scheier, 1981; Greenwald, 1982). Testing interaction predictions of this form provides a means of simultaneously cross-validating taxonomies of both individual differences and social situations (cf. Bem \& Funder, 1978).
3. Clarifying the matching - to - standard process. What criteria do people use in judging the acceptability of response options vis-a-vis behavioral standards? For instance, are symbolic interactionists correct in suggesting that people make behavioral decisions by (a) assessing the identity implications of response options (What kind of person do I appear to be by acting in this way?), (b) choosing the option with those identity implications that they most prefer (cf. Alexander \& Rudd, 1981; Burke, 1980)? Even if this simple model is correct, many issues are left unresolved. What judgmental heuristics do people use to assess both the identity implications of response options and the acceptability of the match between those identity implications and the behavioral standards activated in a situation? How exactly do personality and situational variables activate behavioral standards?

Abandoning the search for decisive empirical confrontations is not therefore a counsel of despair; it suggests alternative, more fruitful lines of empirical inquiry. (Acknowledging what cannot be done empirically often paves the way for what Lakatos, 1970, has called progressive problemshifts.) Nonetheless, some colleagues may doubt the wisdom of the conceptual strategy proposed here and defend the traditional between-theory confrontation approach. They might well reason that the impression management research program is still in its infancy and in need of exposure to competing formulations. We believe, however, that the search for decisive confrontations leads not to a sharpening of theoretical positions, but to even more theoretical confusion and fragmentation, as advocates of each position are increasingly forced to delimit the conditions under which their preferred explanatory account is assumed to hold. The research literature already abounds with experiments designed to operationalize a plethora of theoretical states: inequity distress, reactance, threats to self-esteem, cognitive dissonance, guilt, shame, embarrassment, and so forth. This state of affairs has led Shaw and Costanzo $(1980$, p. 419$)$ to pose the pessimistic question: "Will the field of social psychology eventually fall into an epistemological morass in which theories proliferate to the extent that a single postulate is needed for each possible condition 
in the human social environment?" and to offer the even more pessimistic answer, "To date an affirmative answer is suggested by recent theorizing in social psychology." Instead of adding to this proliferation of minitheories, researchers should focus on those fundamental principles of psychological functioning that have the potential to unify and organize the sprawling mass of research findings within one theoretical framework.

\section{Concluding Remarks}

The growing interest in impression management explanations of social behavior has stimulated many attempts to pit such explanations against well-established intrapsychic accounts for the same phenomena. In this article, we reviewed six methodological strategies that investigators have used to distinguish impression management from intrapsychic explanations. We argued that none of these strategies will yield decisive evidence. Advocates of the competing positions will always be able to account for unexpected findings without abandoning the hard cores of their respective research programs.

The indeterminacy position taken here is similar to arguments that have been advanced in other areas of psychological research. Reviewers of several research literatures have recently expressed skepticism concerning a number of well-known between-theory debates, including those between cognitive dissonance and self-perception explanations of forced compliance effects (Greenwald, 1975), information integration and change - of meaning explanations of impression formation effects (Ostrom, 1977), cognitive and motivational explanations of attribution bias (Tetlock \& Levi, 1982), serial and parallel models of information processing (Anderson, 1978), and propositional and pictorial models of mental imagery (Anderson, 1978). Newell $(1973$, p. 289$)$ has even concluded that the whole practice of testing binary theoretical oppositions in psychological research is misguided (see also Jenkins, 1981; MoGuire, 1983; Meehl, 1978).

The alternative we propose to between-theory confrontation is unification within an abstract and overarching theoretical framework that focuses on psychological processes common to the two classes of explanation and treats points of difference as tractable problems of parameter estimation (e.g., the functional properties of behavioral standards, the nature of the matching-to-standard process). Although we cannot specify the exact form the integrative framework should take, such a framework would provide a badly needed escape from endless partisan debates over the merits of impression management and intrapsychic explanations of research findings.

\section{References}

Alexander, C. N., \& Knight, G. W. (1971). Situated identities and social psychological experimentation. Sociometry, 34, 65-82.

Alexander, C. N., \& Rudd, J. (1981). Situated identities and response variables. In $\mathrm{J}$. T. Tedeschi (Ed.), Impression management theory and social psychological research (pp. 83-103). New York: Academic Press.

Allport, G. W. (1943). The ego in contemporary psychology. Psychological Review, 50, 451-478.

Anderson, J. R. (1978). Arguments concerning representations for mental imagery. Psychological Review, 85 , 249-277.

Arkin, R. M. (1981). Self-presentational styles. In J. T. Tedeschi (Ed.). Impression management theory and social psychological research (pp. 311-333). New York: Academic Press.

Baer, R., Hinkle, S., Smith, K., \& Fenton, M. (1980). Reactance as a function of actual versus projected autonomy. Joumal of Personality and Social Psychology, $38,416-422$.

Baron, R. S., \& Roper, G. (1976). Reaffirmation of social comparison views of choice shifts: Averaging and extremity effects in an autokinetic situation. Journa of Personality and Social Psychology, 33, 521-530.

Baumeister, R. F. (1982). A self-presentational view of social phenomena. Psychological Bulletin, 91, 3-26.

Bem, D. J., \& Funder, D. C. (1978). Predicting more of the people more of the time: Assessing the personality of situations. Psychological Review, 85, 485-501.

Block, J. (1965). The challenge of response sets: Unconfounding meaning, acquiescence and social desirability in the MMPI. New York: Appleton-Century-Crofts.

Borden, R. J. (1980). Audience influence. In P. B. Paulus (Ed.), Psychology of group influence (pp. 99-131). Hillsdale, NJ: Erlbaum.

Brehm, J. W. (1966). A theory of psychological reactance. New York: Academic Press.

Briggs, S. R., Cheek, J. M., \& Buss, A. H. (1980). An analysis of the Self-Monitoring Scale. Journal of Personality and Social Psychology, 38, 679-686.

Burke, P. J. (1980). The self: Measurement implications from a symbolic interactionist perspective. Social Psychology Quarterly, 43, 18-29.

Burnstein, E., \& Vinokur, A. (1977). Persuasive argumentation and social comparison as determinants of 
attitude polarization. Journal of Experimental Social Psychology, 13, 315-332.

Burnstein, E., Vinokur, A., \& Trope, Y. (1973). Interpersonal comparison versus persuasive argumentation: $A$ more direct test of alternative explanations for groupinduced shifts in individual choice. Journal of Experimental Social Psychology, 9, 236-245.

Carsmith, J. M., Collins, B. E., \& Helmreich, R. L. (1966). Studies in forced commpliance: I. The effect of pressure for compliance on attitude change produced by face-to-face role playing and anonymous essay writing. Jotrnal of Personality and Social Psychology, $4,1-13$.

Carver, C. S., \& Scheier, M. F. (1981). Attention and selfregulation: A control-theory approach to human behavior. New York: Springer-Verlag.

Cialdini, R. B., Petty, R. E., \& Cacioppo, J. T. (1981). Attitude and attitude change. Annual Review of $P_{S y}$ chology, 32, 357-404.

Cooley, C. H. (1902). Human nature and social order. New York: Scribner's

Deutsch, M. (1975). Equity, equality, and need: What determines which value will be used as the basis for distributive justice? Joumal of Social Issues, 31, 137150.

Fazio, R. H., \& Cooper, J. (1983). Arousal in the dissonance process. In J. T. Cacioppo \& R. E. Petty (Eds.), Social psychophysiology: A sourcebook (pp. 137-155). New York: Guilford Press.

Felson, R. B. (1981). An interactionist approach to aggression. In J. T. Tedeschi (Ed.), Impression management theory and social psychological research (pp. 181-200). New York: Academic Press.

Fiske, D. W. (1971). Measuring the concepts of personality. Chicago: Aldine.

Funder, D. C. (1982). On assessing social psychological theories through the study of individual differences: Template matching and forced compliance. Journal of Personality and Social Psychology, 43, 100-110.

Gaes, G. G., Kalle, R. J., \& Tedeschi, J. T. (1978). Impression management in the forced complance paradigm: Two studies using the bogus pipeline. Joumal of Experimental Social Psychology, 14, 493-510.

Greenberg, J. (1983). Self-image versus impression management in adherence to distributive justice standards: The influence of self-awareness and self-consciousness. Journal of Personality and Social Psychology. 44, 519.

Greenwald, A. G. (1975). On the inconclusiveness of "crucial" tests of dissonance vs. self-perception theories. Journal of Experimental Social Psychology, 11, 490 499.

Greenwald, A. G. (1980), The totalitarian ego: Fabrication and revision of personal history. American Psychologist, $35,603-618$.

Greenwald, A. G. (1982). Ego task analysis: An integration of research on ego-involvement and self-awareness. In A. Hastorf \& A. M. Isen (Eds.), Cognitive social psychology (pp. 109-147). New York: Elsevier/North Holland.

Greenwald, A. G., \& Breckler, A.I. (in press). To whom is the self presented? In B. R. Schlenker (Ed.), The self in social life. New York: McGraw-Hill.

Greenwald, A. G, \& Ronis, D. L. (1978). Twenty years of dissonance: Case study of the evolution of a theory. Psychological Review, 85, 53-57.

Heilman, M. E., \& Toffler, B. L. (1976). Reacting to reactance: An interpersonal interpretation of the need for freedom. Journal of Experimental Social Psychology, 12. 519-529.

Hogan, R. (1982). A socioanalytic theory of motivation. In M. M. Page (Ed.), Nebraska Symposium on Motivation (pp. 55-89) Lincoln: University of Nebraska Press.

James, W, (1890). Principles of psychology (Vol. 1). New York: Holt.

Jellison, J. M., \& Arkin, R. M. (1977). Social comparison of abilities: A self-presentation approach to decision making in groups. In J. Suls \& R. L. Miller (Eds.), Social comparison processes (pp. 235-257). New York: Halsted.

Jellison, J. M., \& Davis, D. (1973). Relationships between perceived ability and attitude extremity. Journal of Personality and Social Psychology, 27, 430-436.

Jellison, J. M., \& Gentry, K. A. (1978). Self-presentation interpretation of the seeking of social approval. Personality and Social Psychology Bulletin, 4, 227-230.

Jenkins, J. (1981). Can we have a fruitful cognitive psychology? In J. H. Flowers (Ed.), Nebraska Symposium on Motivation, 1980 (pp. 211-238). Lincoln: University of Nebraska Press.

Johnson, J. A. (1981). The "self-disclosure" and "selfpresentation" views of item response dynamics and personality scale validity. Journal of Personality and Sociai Psychology. 40, 761-769.

Jones, E. E., \& Pittman, T, S. (1982). Toward a general theory of strategic self-presentation. In J. Suls (Ed.), Psychological perspectives on the self (Vol. 1, pp. 231 262). Hillsdale, NJ: Erlbaum.

Jones, E. E, \& Sigall, H. (1971). The bogus pipeline: A new paradigm for measuring affect and attitude. $P_{s y}$ chological Bulletin. 76, 349-364.

Kiesler, C. A. (1971). The psychology of commitment. New York: Academic Press.

Lakatos, 1. (1970). Falsification and the methodology of scientific research programs. In I. Lakatos \& A. Musgrave (Eds.), Criticism and the growth of knowledge (pp. 8-101). Cambridge, England: Cambridge University Press.

Lamm, H., \& Myers, D. G. (1978). Group-induced polarization of attitudes and behavior. In L. Berkowitz (Ed.), Advances in experimental social psychology (Vol. 11 , pp. 145-195). New York: Academic Press.

Lindskold, S., \& Propst, L. R. (1981). Deindividuation, self-awareness, and impression management. In J. T. Tedeschi (Ed.), Impression management theory and social psychological research (pp. 201-222). New York: Academic Press.

Linton, R. (1945). The cultural backgrourd of personality. New York: Appleton-Century Co.

McGuire, W. J. (1983). A contextualist theory of knowledge: Its implications for innovation and reform in psychological research. In L. Berkowitz (Ed.), Advances 
in experimental social psychology (Vol. 16, pp. 1-47). New York: Academic Press.

Mead, G. H. (1934). Mind, self, and society. Chicago: University of Chicago Press.

Meehl, P. E. (1978). Theoretical risks and tabular asterisks: Sir Karl, Sir Ronald, and the slow progress of soft psychology. Joumal of Consulting and Clinical Psychology, 46, 806-834.

Mervis, C. G., \& Rosch, E. (1981). Categorization of natural objects. Annual Review of Psychology, 32, 89115.

Morse, S. J., Gruzen, J., \& Reis, H. T. (1976). The nature of equity restoration: Some approval-seeking considerations. Joumal of Experimental Social Psychology. $12,1-8$.

Myers, D. G. (1978). Polarizing effects of social comparison. Journal of Experimenial Social Psychology, 14, 554-563.

Myers, D. G., \& Lamm, H. (1976). The group polarization phenomenon. Psychological Bulletin, 83, 602-627.

Newell, A. (1973). You can't play 20 questions with nature and win. In W. G. Chase (Ed.), Visual information processing (pp. 283-308). New York: Academic Press.

Nisbett, R. E., \& Ross, L. (1980). Human inference: Strategies and shortcomings of social judgment. New York: Appleton-Century-Crofts.

Ostrom, T. M. (1977). Between-theory and within-theory conflict in explaining context effects in impression formation. Journal of Experimental Social Psychology, 13. 492-503.

Page, M. M. (1981). Demand characteristics in laboratory experiments. In J. T. Tedeschi (Ed.), Impression management theory and social psychological research (pp. 57-82). New York: Academic Press.

Paulhus, D. (1982). Individual differences, self-presentation, and cognitive dissonance: Their concurrent operation in forced compliance. Journal of Personality and Social Psychology, 43, 838-852.

Pruitt, D. G. (1971). Choice shifts in group discussion: An introductory review, Journal of Personality and Social Psychology, 20, 336-360.

Regan, D. T., \& Totten, J. (1975). Empathy and attribution: Turning observers into actors. Journal of Personality and Social Psychology, 32, 850-856.

Reis, H. T. (1981). Self-presentation and distributive justice. In J. T. Tedeschi (Ed.), Impression management theory and social psychological research (pp. 269-294). New York: Academic Press.

Riess, M., \& Schlenker, B. R. (1977). Attitude change and responsibility avoidance as modes of dilemma resolution. Journal of Personality and Social Psychology, 35. $21-30$.

Sackeim, H. A. (1981). Self-deception, self-esteem, and depression: The adaptive value of lying to oneself. In J. Masling (Ed.), Empirical studies of psychoanalytic theory (pp. 63-92). Hillsdale, NJ: Erlbaum.

Sanders, G. S., \& Baron, R. S. (1977). Is social comparison relevant for producing choice shifts? Journal of Experimental Social Psychology, 13, 303-314.

Scheier, M. F., \& Carver, C. S. (1980). Private and public self-attention, resistance to change, and dissonance reduction. Journal of Personality and Social Psychology, 39. $390-405$.
Schlenker, B. R. (1980). Impression management: The self-concept, social identity, and interpersonal relations. Belmont, CA: Brooks/Cole.

Schlenker, B. R. (1982). Translating actions into attitudes: An identity-analytic approach to the explanation of social conduct. In L. Berkowitz (Ed.), Advances in experimental social psychology (Vol. 15, pp. 151-181). New York: Academic Press.

Schlenker, B. R., Forsyth, D. R., Leary, M. R., \& Miller, R. S. (1980). Self-presentational analysis of the effects of incentives on attitude change following counterattitudinal behavior. Journal of Personality and Social Psychology, 39. 553-577.

Schlenker, B. R., \& Leary, M. R. (1982). Social anxiety and self-presentation: $A$ conceptualization and model. Psychological Bulletin, 92, 641-669.

Schneider, D. J. (1981). Tactical self-presentations: Toward a broader conception. In J. T. Tedeschi (Ed.), Impression management theory and social psychological research (pp. 23-40). New York: Academic Press

Shaw, M., \& Costanzo, P. (1980). Theories of social psychology (2nd ed.). New York: MoGraw-Hill.

Snyder, M. (1979). Self-monitoring processes. In L. Berkowitz (Ed.), Advances in experimental social psychology (Vol. 12, pp. 85-128). Now York: Academic Press.

Snyder, M., \& Campbell, B. H. (1982). Self-monitoring: The self in action. In J. Suls (Ed.), Psychological perspectives on the self (Vol. 1, pp. 185-208). Hillsdale, NJ: Erlbaum.

Snyder, M., \& Tanke, E. D. (1976). Behavior and attitude: Some people are more consistent than others. Journal of Personality, 44, 510-517.

Sullivan, H. S. (1953). The interpersonal theory of psychiatry. New York: Norton.

Swann, W. B., \& Read, S. J. (1981). Self-verification processes: How we sustain our self-conceptions. Journal of Experimental Social Psychology, 17, 351-372.

Tedeschi, J. T. (1981). Impression management theory and social psychological research. New York: Academic Press.

Tedeschi, J. T., \& Norman, N. (in press). Social power, self-presentation and theself In R R Sehlenker-(fe) The self in social life. New York: MoGraw-Hill.

Tedeschi, J. T., Schlenker, B. R., \& Bonoma, T. V. (1971). Cognitive dissonance: Private ratiocination or public spectacle? American Psychologist, 26, 685-695.

Tedeschi, J. T., \& Rosenfeld, P. (1981). Impression management theory and the forced compliance situation. In J. T. Tedeschi (Ed.), Impression management theory and social psychological research (pp. 147-180). New York: Academic Press.

Tetlock, P. E. (1980). Explaining teacher explanations for pupil performance: A test of the self-presentation position. Social Psychology Quarterly, 43, 283-290.

Tetlock, P. E. (1981). The influence of self-presentation goals on attributional reports. Social Psychology Quarterly, 44, 300-311.

Tetlock, P. E. (1983). Accountability and complexity of thought. Journal of Personality and Social Psychology, 45, 74-83.

Tetlock, P. E., \& Levi, A. (1982). Attribution bias: On the inconclusiveness of the cognition-motivation debate. Joumal of Experimental Social Psychology, 18, 68-88. 
Vinokur, A., \& Burnstein, E. (1978). The depolarization of attitudes in groups. Journal of Personality and Social Psychology, 36, 872-885.

Vinokur, A., Trope, Y., \& Burnstein, E. (1975). A decision making analysis of persuasive-argumentation and choice-shift effect. Journal of Experimental Social Psychology, 11, 127-148.

Weary, G., \& Arkin, R. M. (1981). Attributional selfpresentation. In J. H. Harvey, W. Ickes, \& R. F. Kidd (Eds.), New directions in attribution research (Vol. 3, pp. 225-247). Hillsdale, NJ: Erlbaum.

Wicklund, R. A. (1980). Objective self-awareness. In P. B. Paulus (Ed.), Psychology of group influence (pp. 189-208). Hillsdale, NJ: Erlbaum.

Wicklund, R. A., \& Brehm, J. W. (1976). Perspectives on cognitive dissonance. Hillsdale, NJ: Erlbaum.
Wright, R. A., \& Brehm, S. S. (1982). Reactance as impression management: A critical review. Journal of Personality and Social Psychology, 42, 608-618.

Wyer, R., Hartwick, J. (1980). The role of information retrieval and conditional inference processes in belief formation and change. In L. Berkowitz (Ed.), Advances in experimental social psychology (Vol. 13, pp. 241284). New York: Academic Press.

Zajonc, R. B. (1980). Compresence. In P. B. Paulus (Ed.), Psychology of group infuence (pp. 35-60). Hillsdale, NJ: Erlbaum.

Received February 8, 1984

Revision received May 16, 1984

\section{Instructions to Authors}

Authors should prepare manuscripts according to the Publication Manual of the American Psychological Association (3rd ed.). All manuscripts must include an abstract of $75-100$ words typed on a separate sheet of paper. Typing instructions (all copy must be double-spaced) and instructions on preparing tables, figures, references, metrics, and abstracts appear in the Manual. Also, all manuscripts are subject to editing for sexist language.

APA policy prohibits an author from submitting the same manuscript for concurrent consideration by two or more journals. APA policy also prohibits duplicate publication, that is, publication of a manuscript that has already been published in whole or in substantial part in another journal. Also, authors of manuscripts submitted to APA journals are expected to have available their raw data throughout the editorial review process and for at least 5 years after the date of publication.

Anonymous reviews are optional, and authors who wishanonymous reviews must specifically request them when submitting their manuscripts. Each copy of a manuscript to be anonymously reviewed should include a separate title page with authors' names and affiliations, and these should not appear anywhere else on the manuscript. Footnotes that identify the authors should be typed on a separate page. Authors should make every effort to see that the manuscript itself contains no clues to their identities.

Manuscripts should be submitted in quadruplicate (the original and three photocopies), and all copies should be clear, readable, and on paper of good quality. Authors should keep a copy of the manuscript to guard against loss. Mail manuscripts to the Editor, Martin L. Hoffman, Psychological Review, Department of Psychology, University of Michigan, 3433 Mason Hall, Ann Arbor, Michigan 48109, according to the instructions provided above. 